\title{
DescobrindoSons: um jogo para ensinar música de forma lúdica
}

\author{
Thaisa Napolitano $^{1}$, Gustavo Paiva Guedes ${ }^{2}$ \\ ${ }^{1}$ UFRJ - Universidade Federal do Rio de Janeiro \\ Av. República do Chile, 330 - Rio de Janeiro - RJ - Brasil \\ ${ }^{2}$ CEFET/RJ - Centro Federal de Educação Tecnológica Celso Suckow da Fonseca \\ Av. Maracanã, 229 - Rio de Janeiro - RJ - Brasil. \\ thaisa_napolitano@hotmail.com, gustavo.guedes@cefet-rj.br
}

\begin{abstract}
The teaching of music in schools aims to expand the access and quality of the artistic experience of the students involved. However, the teaching of music has other objectives, such as the development of motor coordination, listening, concentration, social skills, among others. Considering these objectives together with the advancement of technology, we can use technological devices as support to facilitate the dynamics of the classes. Technology coupled with a playful approach can bring benefits to the teaching/learning process. In this scenario, a game called DescobrindoSons was developed, which aims to teach children musical instruments in a playful way and with the aid of technology.
\end{abstract}

Resumo. $O$ ensino de música nas escolas possui o objetivo de expandir o acesso e a qualidade da experiência artística dos alunos envolvidos. No entanto, o ensino da música possui outros objetivos, como o desenvolvimento da coordenação motora, escuta, concentração, habilidade social, dentre outros. Considerando esses objetivos juntamente com avanço da tecnologia, podemos usufruir de aparelhos tecnológicos como suporte para facilitar a dinâmica das aulas. A tecnologia somada a uma abordagem lúdica pode trazer benefícios ao processo de ensino/aprendizagem. Nesse cenário, foi desenvolvido um jogo denominado DescobrindoSons, que tem o objetivo de ensinar sons de instrumentos musicais a crianças de maneira lúdica e com o auxílio da tecnologia.

\section{Introdução}

A educação musical vem adquirindo um papel importante no ensino básico, embora o ensino da música ainda seja visto como o ato de cantar canções para possuir conhecimento e com o fim de criar apresentações em datas festivas [de Brito, 2003]. No entanto, o ensino musical vai muito além, pois com seu conteúdo histórico e sociológico, a música se caracteriza como um fenômeno universal, podendo ser expressa de diversas formas, baseando-se na cultura em que está inserida [de Brito, 2003]. Segundo concepções pedagógicas, a educação musical tem sido incorporada na educação infantil brasileira para atender propósitos distintos, como ampliar e desenvolver processos cognitivos como o pensamento, a atenção, o raciocínio, a memória, a disciplina, a imaginação, a percepção visual e audível, a consciência, as emoções e a aprendizagem [de Brito, 2003].

Segundo Piaget [1954], que aborda o desenvolvimento artístico da criança, a produção musical e corporal representa uma abordagem de junção das necessidades de 
VII Congresso Brasileiro de Informática na Educação (CBIE 2018)

Anais do XXIX Simpósio Brasileiro de Informática na Educação (SBIE 2018)

expressão do "eu" e dos desejos infantis. A criança se comunica desde cedo por meio das linguagens artísticas, entretanto quando são inseridas na escola, o aprendizado se torna algo pronto, sem desafiar a capacidade de desenvolvimento de cada criança. Com isso, o ensino da música deve dar a oportunidade da criança se expressar corporalmente e construir seu conhecimento musical desenvolvendo suas potencialidades. Somado a isso, com o avanço da tecnologia, a música tem se tornado cada vez mais presente no dia-a-dia e tem sido incorporada em diversas disciplinas, muitas vezes de forma lúdica [Herrera et al., 2008].

O lúdico pode ter um importante papel na aprendizagem, não só no ensino da música, mas na educação em geral [Gomes, 2015]. O ensino lúdico pode motivar os alunos favorecendo experiências e vivências em atividades que podem estar atreladas ao conteúdo a ser absorvido. Atividades lúdicas, como jogos ou aplicativos possuindo caráter educativo e utilizados como apoio para o professor em sala de aula, podem despertar o interesse e motivação dos alunos [Gomes, 2015]. Ainda segundo o autor, o uso de brincadeiras lúdicas e todo conteúdo didático precisam ser analisados com relação a importância, o porquê e para que, analisando juntamente o perfil dos alunos, o planejamento das propostas, que deverão ser coerentes com os objetivos dos conteúdos, além de analisar também os recursos disponíveis em sala e o contexto cultural.

Caracterizando um sentido de ação, o jogo dá ao aluno a liberdade de jogar, deixando-o livre para pensar, agir e interagir, sendo absorvido inteiramente pelo jogo, mesmo que existam regras e maneiras de jogar [Huizinga, 2000]. O mais interessante do jogo é que é algo que pode ser fixado imediatamente e caso o aluno não absorva o conteúdo da maneira adequada, o jogo pode ser repetido diversas vezes criando novas vivências e experiências, até mesmo novas interações com o objeto, com o jogador, com os colegas e com o conteúdo apresentado [Huizinga, 2000].

O lúdico sugere o sentido de brincadeira, prazer e descontração; sem reflexão das propostas e planejamento do conteúdo, ele perde seu sentido e os alunos podem se sentir presos e limitados [Galamian and Thomas, 2013]. Quando há absorção da vivência e do conteúdo em questão, a criança constrói seu próprio pensamento, experimentando regras de comportamento que ajudam na atividade lúdica e que podem melhorar diversas habilidades sociais.

Buscando maior interatividade e motivação dos alunos, dispositivos e aplicativos têm se tornando um aliado do professor. Pensando nisso e buscando integrar o ensino de música com a tecnologia, o presente estudo apresenta um aplicativo que possui o propósito de ensinar o conteúdo musical que está sendo explorado em sala de aula para crianças entre 5 a 12 anos. Da mesma forma que a música estabelece um vínculo especial com a concentração e a atenção, o jogo sensório-motor DescobrindoSons pode ajudar na absorção de conteúdos e no desenvolvimento das habilidades cognitivas descritas nos parágrafos anteriores. O jogo consiste em executar um som de instrumento musical para que o aluno descubra, pelo timbre, qual instrumento está sendo tocado. Além do som, o jogo apresenta quatro figuras de instrumentos na tela do dispositivo, dentre as quais, uma figura corresponde à representação do instrumento musical relacionado ao som tocado. $\mathrm{O}$ aplicativo pode ser usado de diversas maneiras e em distintas situações, desde aulas particulares até os ambientes escolares. 
VII Congresso Brasileiro de Informática na Educação (CBIE 2018)

Anais do XXIX Simpósio Brasileiro de Informática na Educação (SBIE 2018)

O restante desse artigo está divido em mais três seções. Após a introdução desse trabalho, a Seção 2 apresenta alguns trabalhos relacionados ao presente estudo. A Seção 3 aborda o jogo desenvolvido (DescobrindoSons). Por fim, a Seção 4 traz as considerações e os trabalhos futuros.

\section{Trabalhos Relacionados}

O trabalho proposto por Bordini et al. [2015] apresenta um jogo educacional denominado Musikinésia. O jogo possui o objetivo de auxiliar os alunos de cursos de música a identificar as teclas de um teclado musical. Além disso, tem o objetivo de ensinar conceitos musicais básicos, como andamento e leitura musical.

Em Motta and Garone [2013], foi desenvolvido o jogo Melodic. O objetivo principal desse jogo é estimular a musicalidade do jogador e aumentar capacidade de ouvir as relações musicais com precisão e entendimento. Além disso, o jogo objetiva que os jogadores fiquem mais habituados aos sons das notas musicais, efetuando um treinamento auxiliar de ditado melódico.

Sampaio et al. [2014] desenvolveram um jogo com objetivo de possibilitar que as crianças surdas vivenciem a música de forma prazerosa. O contexto do jogo ocorre com elementos do folclore brasileiro. A ideia é utilizar caixas de som amplificadas e um piso de madeira para que o piso receba a pulsação rítmica. Dessa maneira, as crianças podem perceber a musica da sua maneira.

Diferente dos trabalhos apresentados, o DescobrindoSons tem como um dos objetivos o ensinamento do som de diferentes instrumentos às crianças. Mais que isso, o objetivo é que isso ocorra de uma forma lúdica em grupos de alunos e com a mediação sendo realizada pelo professor.

\section{DescobrindoSons: o jogo}

O DescobrindoSons é um jogo de escuta, em que o jogador/aluno deve prestar atenção ao som tocado e tentar adivinhar, pelo timbre, qual instrumento está emitindo o som. O objetivo principal do aplicativo é desenvolver a concentração dos alunos na escuta de timbres. Como objetivos secundários, pode-se destacar outras habilidades importantes para o desenvolvimento social da criança, por exemplo, obedecer as regras, respeitar a escuta de outro participante do jogo, aguardar a sua vez de jogar, além de gerar uma interação com outros colegas e participantes.

O jogo foi idealizado para turmas pequenas, com um número entre 6 e 10 alunos. A dinâmica do jogo ocorre da seguinte maneira: são divididos pequenos grupos de alunos, em que cada grupo possui um tablet com o jogo instalado. Em seguida, o jogo é iniciado pelos grupos e, cada grupo, vê na tela do jogo quatro instrumentos que são apresentados aleatoriamente, conforme ilustrado na Figura 1. Juntamente com isso, é tocado um som. É importante ressaltar, que um dos instrumentos apresentados corresponde ao som tocado. O objetivo dos jogadores é escolher qual instrumento está relacionado ao som tocado.

Cada grupo inicia com 3 vidas e a cada vez que acerta o som, ganha uma vida e avança para a próxima fase. Caso erre, o grupo perde uma vida, podendo tentar acertar novamente até que suas vidas acabem. Caso o grupo perca, os jogadores visualizam uma tela com a pontuação e um espaço para inserirem o nome do grupo, para serem incluídos em um ranking. O grupo vencedor será o que avançar mais fases. 
VII Congresso Brasileiro de Informática na Educação (CBIE 2018)

Anais do XXIX Simpósio Brasileiro de Informática na Educação (SBIE 2018)
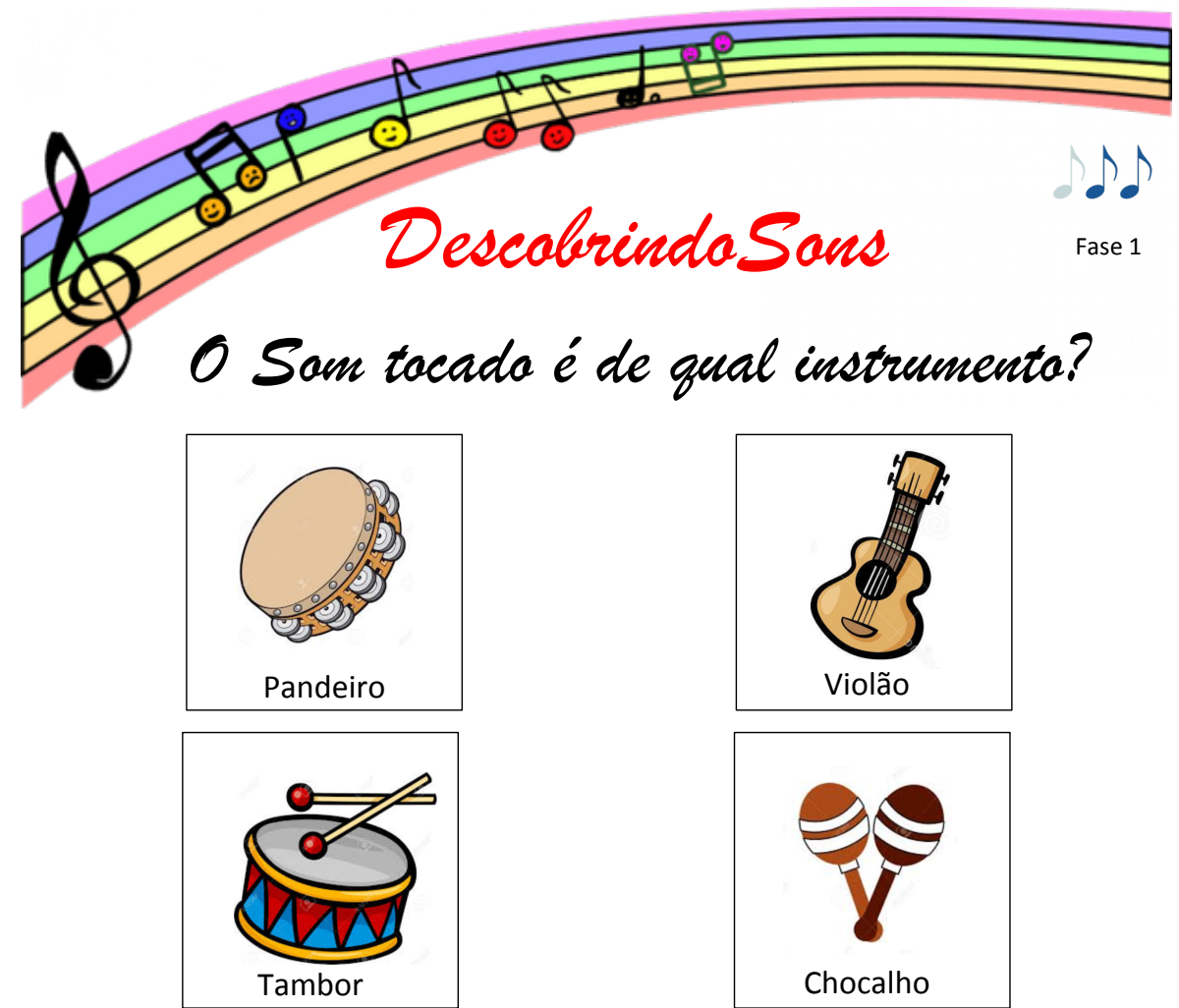

Figura 1. Tela do jogo DescobrindoSons. São apresentados quatro instrumentos e é tocado um som que corresponde a um dos instrumentos. O objetivo dos jogadores é escolher a qual instrumento corresponde o som tocado.

\section{Considerações e trabalhos futuros}

Este artigo apresentou o jogo DescobrindoSons, que tem como objetivo auxiliar o educador musical a ensinar os conteúdos musicais aos alunos. DescobrindoSons tem o intuito de mostrar também que o lúdico tem papel importante no aprendizado, motivando o professor a incorporar atividades de mesma natureza, podendo gerar prazer, interesse e motivação para seus pupilos.

O jogo tende a ser bem aproveitado, expandindo habilidades do sentido auditivo, social e ampliação dos conhecimentos culturais. Nas próximas versões, pretendemos inserir níveis para alunos mais avançados, como a escuta simultânea de dois ou mais instrumentos. Além disso, a ideia é inserir também fases extras, que irão abordar as famílias dos instrumentos.

O objetivo é que cada fase extra seja destinada a uma família instrumental, uma apenas para instrumentos de sopro, outra para instrumentos de cordas e outra para os instrumentos de percussão. Essas fases extras não possuirão apenas o intuito de aumentar o nível de dificuldade. Cada fase terá o objetivo de desenvolver a audição, apurando o ouvido, a atenção e a concentração na escuta de timbres de instrumentos de mesma família e com timbres parecidos. Mesmo tendo o intuito de ser usado em escolas, o jogo DescobrindoSons pode ultrapassar as paredes do ambiente escolar, podendo ser utilizado para o lazer em família. 
VII Congresso Brasileiro de Informática na Educação (CBIE 2018)

Anais do XXIX Simpósio Brasileiro de Informática na Educação (SBIE 2018)

\section{Referências}

Bordini, R. A., Otsuka, J., Beder, D., Fonseca, L. F., de Freitas, P. A. G., Nunes, A. P. A., Santiago, D. L., and Santiago, G. (2015). Musikinésia: Jogo eletrônico para o aprendizado de teclado musical. In Brazilian Symposium on Computers in Education (Simpósio Brasileiro de Informática na Educação-SBIE), volume 26, page 647.

de Brito, T. A. (2003). Música na educação infantil: propostas para a formação integral da criança. Editora Peirópolis.

Galamian, I. and Thomas, S. (2013). Principles of violin playing and teaching. Courier Corporation.

Gomes, É. D. (2015). Brincando com os sons: refletindo sobe o lúdico na educação musical.

Herrera, I. M. A., del Castillo Ferreira, M., la reciente publicación en España, T., and de la Ley Orgánica de Educación, L. (2008). Música, interdisciplinariedad e inclusión social. el friso sonoro como propuesta de aplicación en el aula. Atividades lúdicas em contextos culturais: interdisciplinaridade e inclusao, pages 127-136.

Huizinga, J. (2000). Homo ludens ( $4^{\text {a }}$ edição.). Perspectiva.

Motta, F. and Garone, E. (2013). Melodic: design instrucional de um jogo para o ensino de música. Proceedings of SBGames 2013. Art \& Design Track.

Piaget, J. (1954). Language and thought from a genetic perspective. Acta Psychologica, 10:51-60.

Sampaio, A. S., Angelim, A. M., Gadelha, A. S., Chaves, E. M., Braga, P. B., Munguba, M. C., and Junior, R. B. L. (2014). Toc tum: Desenvolvimento de jogo para a mediação da iniciação musical do surdo com aporte terapêutico ocupacional. Proceedings of SBGames 2014. 